\title{
ECOS DE UM CORPO (DES)VIADO ${ }^{i}$
}

Nadson Fernando Nunes da Silva ${ }^{\text {ii }}$ Maria dos Remedios de Brito ${ }^{\text {iii }}$

\begin{abstract}
Resumo: A escrita compõe-se sobre as marcas vivas do corpo, aproximando-se da Filosofia da Diferença de Deleuze e Guattari para pensar a educação e a sexualidade em seu percurso experimental, sendo a mesma, fio condutor metodológico que delineará uma escrita de si desarmando os marcadores sociais de uma existência bicha em sala de aula. A escrita tomará as linhas de fuga para deslocar os olhares educacionais, deixando vazar por uma nova imagem de corpo-professor apontando para a ideia de que os vazamentos agem a partir das experimentações, tecendo o corpo-masculino para além dos lugares convencionais, aproximando-o do corpo-devir-viado. Esse processo se localiza dentro da minha experiência como professor de ciências, com objetivo de trazer o corpo e sua diferença como ação inventiva para pensar os processos que se dão na docência, e assim alcançar uma educação-movediça com possíveis aberturas que dialogue entre modos de ser e ensinar.
\end{abstract}

Palavras-chave: Corpo; Filosofia da diferença; Docência-(des) viado; Educação.

\section{ECHOES OF A DIVERTEND BODY}

Abstract: The writing is about the alive marks of the body, approaching it to Deleuze and Guattari's Philosophy of Difference to think on the education and sexuality in their experimental way; thus the methodological thread of this writing will delineate a writing of itself disassembling the social markers of a gay existence in classroom. Therefore, the writing will take lines of escape to dislocate the educational eyes, leaving to leak by a new image of the body of teacher, pointing the idea that the leakages take action from experiments, and taking the male body beyond the conventional places, approximating it of the gay body. This process is identified from my experience as science teacher; it also aims to bring the body and its difference as an inventive action to think about the processes which take place in teaching and, thus, achieving an education with possible openings that dialogue between ways of being and teaching.

Keywords: Body; Difference Philosophy; Teaching; Education.

\section{Palavras fragmentadas...}

... são possíveis pontos de entrada não sendo início ou mesmo fim. A escrita é uma possibilidades de potências que constroem-se pela força do desejo de existir, rasgando o verbo para se (re)inventar, criando suas próprias aberturas, como nos disse Deleuze e Guattari (1977, p. 28-29) "escrever é cavar como um cão, que faz seu buraco, um rato que faz sua toca (...) e 
assim, encontrar seu próprio ponto de subdesenvolvimento, seu próprio patoá, seu próprio terceiro mundo, seu próprio deserto".

Indo ao encontro da Filosofa da diferença de Deleuze e Guattari podemos nos perguntar como abrir-se para uma escrita de si? Quais palavras seriam possíveis para dizer-lhes os sentidos do corpo? E por quais linhas se (de)compõe?

Diante desses pontos de interrogações, escrever não é certamente impor uma forma (de expressão) para um corpo vivo, mas toma-la como processo inventivo, criador, movente, num devir sempre inacabado, continuamente em via de fazer-se, e que extravasa qualquer matéria vivível ou vivida, é abrir-se entre passagens de uma vida. "A escrita é inseparável do devir; ao escrever, estamos num devir-mulher, num devir-animal ou vegetal, num devir-molécula, até num devir-imperceptível" (DELEUZE, 1971, p.11).

Escrever é alguma coisa mais do que um adestramento de si mesmo como nos coloca (FOUCAULT, 2004). Compreendendo que a escrita se constitui de certa maneira como uma manifestação de nós mesmos e para os outros, é uma forma de "se mostrar", se expor, fazer aparecer os contornos do seu próprio rosto perto do outro.

Por isso, criam-se linhas pulsantes que desdobram às páginas (re)criando a si mesmo como corpo buraco, onde se cavam os caminhos na busca de novas descobertas, partindo ao encontro de outras potências existenciais, movido de seu próprio desejo, trazendo para si uma escrita movente, diluída diante das manifestações das estruturas sociais.

Pela escrita de si o corpo vaza e torna-se outros, um corpo movediço, que engole a densidade, introduzindo-se pelas entrelinhas, tomando as palavras por um processo de deslocamento, causando sempre aberturas, desalinhando os fios para gerir suas outras formas, criando-se num fluxo contínuo e desejante, indiscernível e sempre pronta a se refazer, germinando outras escritas. "Uma escrita-floração" (AQUINO, 2011, p. 649).

Contornar as linhas, delinear o espaço em branco dessas páginas é compor os devaneios desse corpo (des)viado que ao fragmentar sua existência alcança as palavras fazendo o pensamento correr entre linhas e vivências. A escrita escapa dos movimentos do pensamento e toma suas infinitas formas para dar sentido e significado às coisas do mundo. Como nos enunciou (DELEUZE, 1971, p. 43) "a palavra eu não a vejo, eu a invento", onde a expressão nos leva a despedaçar as formas enrijecida, rompendo com a ordem do sistema.

Portanto, retomar as palavras no desejo de traçar uma trajetória que atravessa o corpo e seus processos de vivências por entre linhas e riscos que possam vir a (de)formar as amarrações do corpo para a articulação de uma docência mais solúvel que brota das entranhas do corpoviado, revelando para si e para o outro formas de agir, diluindo suas bases para que escape do Revista Interinstitucional Artes de Educar. Rio de Janeiro, V. 7, N. 1 - pág. 272-292 janeiroabril de 2021: "Pedagogias Vitais: Corpo, Desejo e Educação" DOI: 10.12957/riae.2021.54627 
pensamento não retilíneo das coisas, criando outros caminhos, não com intuído de uma chegada, pois a educação é móvel e o desejo é não chegar, mas sim, ativar as potências que circundam ao meio e o meio é corpo, é pensamento, é variação constante. Deixar que essas variações nos afetem, contaminem cada membrana, cada poro, cada órgão. Deixar que os olhos não mais sejam olhos, que as mãos não mais sejam mãos, que a boca não seja mais boca, que a pele não seja mais pele, como um poeta-tocador escreveu: "apenas sejam" (MATOS, 2013, p. 41).

Existir pelas agitações dos desejos, que infiltram e vazam as formas, encarando a escrita como pele que reveste o texto, rasgando a carne, deixando fluir na veia, incorporando ações inventivas que causam um mover-se para além das linhas e margem do papel. Nesse sentido, Deleuze e Parnet (1998) é possível que escrever esteja em uma estreita relação com as linhas de fuga. Escrever é traçar linhas de fuga, é tornar-se, entretanto é de modo algum tornar-se escritor. É tornar-se outra coisa, outras coisas, como uma espécie de desterritorialização de força, que faz correr as linhas movimentando-se para outros lugares, um fora de si.

A escrita se manifesta como saída da razão sedentária, em prol de uma razão andante, nômade, capaz de fazer saltos, percursos, travessias, desmobilizar sistemas, verdades, certezas e finalidades (BRITO, 2011). Ela cava, entra, fere, faz dobraduras, escapam por entre possíveis rachaduras. A escrita é cambiante, não segue uma linha reta, ela rodopia na multiplicidade da sua energia. A escrita é descentralizada de um lugar dito "lugar da verdade", por isso ela precisa ser deslocamento das ideias, das palavras, do pensamento e do corpo. Pode-se dizer como Foucault (2001, p. 269)

[...] a escrita se libertou do tema da expressão: ela se identifica com sua própria exterioridade desdobrada. Essas regularidades da escrita são sempre experimentadas no sentido de seus limites, ela está sempre em vias de transgredir e de inverter a regularidade com a qual se movimenta.

A escrita se desenrola como um jogo que vai além de suas regras, passando para fora. Torna-se outra coisa, que não tem denominação, dominação, por isso cria-se para escapar, deslizar, infiltrar, despedaçar, ecoar e desejar, como um corpo que vai sendo distorcido numa mudança de estado, decentralizando a forma, causando buracos metamórficos como o corpo elástico de Alice no país das Maravilhas, de Lewis Carroll (2002), ou do corpo do caixeiro viajante Gregor Samsa no texto A metamorfose, de Kafka (1997). Nesses escritos, modos de vida são inventados, esvaziando o corpo para dar lugar a outras formas de vida, numa existência trânsito entre carne e fuga desejante. 
A desconfiguração da imagem-corpo que passa por variadas modulações, dando origem a outras composições de si, por conexões que causam colisões, procurando sempre se fazer por outros ângulos, desalinhando o corpo numa escrita viva, se fazendo entre as linhas como nos coloca (DELEUZE; GUATTARI, 1996).

As linhas de fuga são criações desejantes por onde o corpo se esboça, criando suas fissuras, vazamento de suas singularidades, subjetividade deslocada. Vazamentos que dão passagens para múltiplas aberturas, dos traços não retilíneos, dos verbos que rodopiam criando suas próprias impressões. Das linhas de fuga surgem travessias de um corpo escrito no limiar de uma vida pontuada nos mergulhos das linhas e dos fios que se desfaz ao se (re)inventar.

A escrita-autobiográfica pode fabricar um movimento-devir, aliais, ela é isso mesmo, sem núcleo central, não segue uma linha reta. Propõe-se que, em lugar das articulações, dos organismos, dos estratos, das territorialidades, se faça dessa viagem autobio linhas de fuga, movimento de desterritorialização/desestratificação, que se façam riachos e escoamentos e que se multiplique a vida e se faça passar a diluição do organismo, produzindo partículas, intensidades. (BRITO, 2011, p.248)

Fazer correr tais linhas, movimentar o pensamento para outros lugares, para um fora de si, tornar-se por novos territórios, novas descobertas, possíveis de outras entradas. Delinear linhas de vida, na arte dos encontros, deslizando para não se fixar como corpo acabado no ato de escrever. Nada está pronto, nenhuma escrita define a forma, nenhum corpo é por completo um corpo, nenhum pensamento é acabado, nenhum final de página é o fim de uma escrita.

Por esses pontos descontínuos, o corpo demarca a docência, justamente para quebrar a barreira de uma verdade fixa, tomando a educação como percurso de (de)composição. Um corpo-docente-des(viado) que emerge dos rios, de comunidade tradicional amazônida, que é viado de água doce, águas de Taquandeua ${ }^{\text {iv }}$, adentrando a escola - E.E.E.F. José Maria Machado Cardoso, transcendendo a imagem binaria do jogo social. Um incomodo das cadeiras escolares, corpo estranho a frente das aulas de ciências o qual corrompe os muros, escorre pelos corredores da aprendizagem e (re)cria o seu lugar na educação, deformando a forma, deslocando-se no desejo de resistir. Nesse viés, ZAMBONI (2013, p. 06) pontua

a filosofia como bicha, ou a bicha como filósofa traça uma linha crítica entre as coisas e interroga-lhe as relações, para que se possam inventar outros modos de viver e pensar. Em meio a esse despropósito é que a bicha se faz personagem conceitual para uma Filosofia da diferença. 
Assim, esse processo fecundo segue numa linha de escrita móvel, diluída em seu percurso criador, que é vida, caos, desordem, atravessamentos das linhas irregulares, pois não se sabe quais caminhos serão cavados nas próximas páginas, ou mesmo quais palavras irão dizer alguma coisa. Seguimos deslizando os fios, navegando, fluido como rio, por essas águas Amazônida.

\section{Bicha afrontando metodologia,}

...é isso que esboçamos aqui. O corpo em seu percurso varia, mostra-se em contornos desarticulados pelo olhar do outro, digerido entre as vozes que marcam o lugar da diferença, que na passagem dos movimentos de si, também se faz resistência.

Por meio da metodologia da diferença, dilatamos a imagem do masculino na possibilidade do encontro de palavras, da escrita com corpo, nos contornos de linhas vivenciadas no instante, retirando as velhas armaduras que recobrem a essência, germinando novas formas de existir. Esses movimentos são condições para sentirmos como o mundo é, portanto, um dos principais modos como aprendemos a significar-nos (GREINER, 2011).

São vozes que causam ecos, apropriando-se do corpo que é gay, bicha, viado, afeminado, aluno, professor, pesquisador, afirmando-se em um verbo de existência, onde a diferença se situa, assumindo aspecto de uma (re)descoberta, empoderamento os quais rasgam o pejorativo, e apresentam-se como corpo-lugar, nascendo bichas e bichonas. O que bem nos apresenta (ZAMBONI, 2016, p. 13), "não existe o ser bicha, apenas devir bicha, uma existência paradoxal que corrói as formações do ser". Por isso, a bicha ao confrontar a metodologia de escrita torna-se movediça, criando saídas e entradas, ingerindo sua estrutura, não como novos princípios, mas como alguns cortes, sendo métodos que se fazem por vias de sensações, arquitetando antes é uma provocação ao pensamento, como prazeres da (cria)AÇÃO.

\section{A ciência escreve sobre o corpo...}

...alinhando marcas de seus feitos, achados, produção, numa decorrência de veracidade inscrita, colada e estruturada.

A ciência é um achado, uma saída, mas também é um código, um mistério, uma produção e interpretação no pensamento. A ciência escreve, alinha os fios, pontua as cores, Revista Interinstitucional Artes de Educar. Rio de Janeiro, V. 7, N. 1 - pág. 272-292 janeiroabril de 2021: "Pedagogias Vitais: Corpo, Desejo e Educação" DOI: 10.12957/riae.2021.54627 
codifica as texturas, perfura a experiência, cola as figuras, desenha, formula, experimenta, destina e confirma pelo efeito do que é verídico, se deleitando sobre os versos da verdade, não cabendo estar entre aspas, pois reproduz e estabelece por ela mesma esse status de verdade absoluto. Suas estruturas são páginas escritas, descobertas, exercício do conhecimento, um diálogo entre mundo, modos de olhar e estar na camada social. É um estado sólido da matéria, ela se firma, se afirma. É uma causa que gera infinitas perguntas e que consequentemente dará respostas. Ela corre por linha linear, ela não esbarra. Ela gesta e vive das ideias, formulações da dúvida. Ela busca decifrar e codificar as incertezas. A ciência nomeia. É um campo de forças, um acontecimento.

A ciência se projeta, proporciona uma imagem exata do mundo. Um passado, presente e futuro. Um começo, meio e fim. É um efeito, um feito. O corpo é produção desses escritos, fórmulas e formas. Há um mapa-destino desenhado para os sexos que são consumidos pelas categorias biológicas: órgãos genitais, cromossomos sexuais e hormônios com os quais se nascem.

O corpo humano é o primeiro lugar onde a sociedade sempre leu a priori, encarandoo como uma espécie de escrita viva, onde as interpretações são locadas por dominação. Nesse sentido Louro (2000) aponta que o corpo é esse "dado" ao nascer; ele é um legado que carrega "naturalmente" certas características que trazem uma determinada forma, que possui algumas "marcas" distintivas. Nessa perspectiva, o corpo não somente "dado", mas também produzido, cultural e discursivamente, e, nesse processo, ele adquire outras "marcas". As formas de intervir nos corpos ou de reconhecer a intervenção irão variar conforme a perspectiva assumida. Em consonância com LOURO (2000, p. 61):

Observar os corpos, avaliar, medir, classificar, pontuar, dar-lhes uma ordem; corrigi-los sempre que necessário, moldá-los às convenções sociais. Fazer tudo isso de forma a que se tornem aptos, produtivos e ajustados - cada qual ao seu destino, um trabalho incessante, onde se reconhecem - ou se produzem - divisões e distinções.

Nos limites desses termos, o corpo aparece como um meio sobre o qual se inscrevem significados, um processo que ao supor "marcas" corporais, as faz existir, inscrevendo e instaurando diferenças, ou então como o instrumento pelo qual uma vontade de apropriação ou interpretação determina o significado por si mesmo (BUTLER, 2003, p.27).

Esses significados acabam por demarcar o corpo como espaço privado, de propriedade alheia, no qual agulhas perfuram às camadas da pele, costurando formas únicas de compreender a si. Uma penetração cortante das ordens retilíneas que determinam espaços e modos de ocupar. 
Agulhas afiadas que alcançam o vazio do corpo adentrando suas estruturas e traçando amarrações.

Podemos nos perguntar com quais ferramentas se escreve e produz corpos distintos? Em quais circunstâncias?

O corpo é nomeado, ele é um sexo a priori, um órgão genital, um símbolo $\left(X Y^{v}\right)$, códigos específicos do campo biológico do corpo.

O corpo é um texto socialmente construído, um arquivo orgânico da história da humanidade como história da produção- reprodução sexual, na qual certos códigos se naturalizam, outras ficam elípticos e outras são sistematicamente eliminados ou riscados. (PRECIADO, 2014, p. 26)

Sobre o corpo é atribuído um tipo de escrita, uma normalidade, um sexo, uma identidade, um gênero que consequentemente resulta em uma identidade, singular das amarrações sociais e biológicas. Na sociedade arquitetura do corpo é política e a identidade é heterossexual reproduzindo uma imagem homem e uma imagem mulher, vias das transposições binárias, sendo ela uma tecnologia fundada nos sexos.

Assim, pensar o corpo como multiplicidade existencial é problematizar para compreendermos o consentimento compacto das ciências, do qual não somente estabelece um montante de células, órgãos e vasos sanguíneos, pois é vê-lo enquanto identidade, como uma invenção, e que constantemente fala, questiona, oscila e passa a existir (SILVA; VALENÇA, 2016).

O corpo busca maneiras de se esquivar, curvar à "normalidade" dirigida a reprodução sistemática da ordem, desmonta as linhas do sexo, linhas de gênero, para construir linhas desejantes. "Não existem pessoas face a face, identificáveis por seu sexo, mas sempre a agitação de partículas singulares" (SCHERER, 2016, p.149).

Portanto a construção do gênero também se faz por meio de sua desconstrução (BUTLER, 2003, p. 25)

Aquilo que permanece fora do discurso como um trauma em potencial que, se/ quando não contido, pode romper ou desestabilizar qualquer representação. $\mathrm{O}$ próprio gênero se torna um artifício flutuante, com a consequência de que homem e masculino podem, com igual facilidade, significar tanto um corpo feminino como um masculino, e mulher e feminino tanto um corpo masculino como um feminino. 
O corpo torna-se esse lugar em que convergem sistemas abertos onde a permeabilidade, infiltração, constituem os deslizes por entre os sexos. É mister de um sexo vazado, de um corpo fissurado, desconfigurações das nomeações heterossexuais das normas.

A homossexualidade escorre pelas linhas abre o corpo desfiando o gênero, decomposição-homem. Não se trata mais de homem ou mulher, mas de inventar o sexo (DELEUZE, 2004). A homossexualidade vai se abrir a todas as espécies de relações novas possíveis, micrológicas ou micropsíquicas, essencialmente reversíveis, transversais, com tantos sexos quanto há agenciamentos.

A homossexualidade "é uma incorporação de desordem" (FOUCAULT, 1988, p.42), ponto cruzado das linhas delirantes, possíveis para as aberturas, reinscrevem efetivamente as fronteiras do corpo em conformidade com suas novas linhas desejantes.

O corpo pelo desejo da carne risca a classificação ho.mem ${ }^{v i}$, molhando as páginas do biológico. Emaranhado de outros corpos, sem nomenclatura para definir, código errante. Um corpo emparelhado aos processos descontínuos dos sexos, do gênero desviado, desajuste das partículas homem, desconfiguração dos verbos ordenados, mutilação da "norma".

Dado que aquilo que se invoca como "real masculino" e "real feminino" são construções do meio discursivo da ordem da contrassexualidade, e também de uma teoria do corpo que se situa fora das oposições homem/mulher, masculino/feminino, heterossexualidade/homossexualidade.

A contrassexualidade que Preciado (2014, p.22) define a sexualidade como tecnologia.

Os diferentes elementos do sistema sexo/gênero denominados "homem", "mulher", "homossexual", "heterossexual", "transexual", bem como suas práticas e identidades sexuais, não passam de maquinas, produtos, instrumentos, aparelhos, truques, próteses, redes, aplicações, programas, conexões, fluxas de energia e de informação, interrupções e interruptores, chaves, equipamentos, formatas, acidentes, detritos, mecanismos, usas, desvios.

Os corpos reconhecem a imagem de si mesmo, não como homens ou mulheres, e sim como corpos falantes, e reconhecem os outros corpos como pontos existentes. Portanto é pungente reinventar nosso próprio corpo. Um corpo que não esteja moldado por funções e sim por intensidades. Um corpo que dê passagem aos fluxos vitais. Se no Anti-Edipo Gilles Deleuze e Félix Guattari (2010), o conceito de Corpo sem Órgão é apresentado como uma Ontologia, um plano de imanência; a partir de Mil-Platôs, o CsO apresentado como uma possibilidade Ética, criação de um corpo sem órgão para si. Nessa perspectiva, como seres viventes estamos numa formação social. O que não passa de uma organização estratificada para nós, em nós, no Revista Interinstitucional Artes de Educar. Rio de Janeiro, V. 7, N. 1 - pág. 272-292 janeiroabril de 2021: "Pedagogias Vitais: Corpo, Desejo e Educação" DOI: 10.12957/riae.2021.54627 


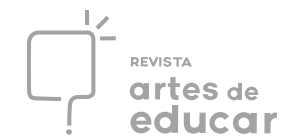

lugar onde estamos, criando fronteiras, indo dos estratos ao agenciamento mais profundo em que estamos envolvidos, fazendo com que o agenciamento oscile delicadamente, fazendo-o passar do lado do plano de consistência. É somente aí que o $\mathrm{CsO}$ de se revela pelo que ele é "conexão de desejos, conjunção de fluxos, continuum de intensidades" (DELEUZE; GUATTARI, 1996, p. 22).

Tudo isso é manifestar para si um corpo sem órgão. Torna-se um entre-lugar, um agenciamento de elementos, homens, animais, vegetais, moléculas. O CsO se manifesta por tudo isso, torna-se um plano, um coletivo, agenciamentos, vibrações. Somos potências, fragmentos, porque não existe "meu" corpo sem órgãos, mas "eu" sobre ele (DELEUZE; GUATTARI, 1996).

O que resta do "eu”? Cambiantes e imutáveis limiares. Não se trata aqui de entender o corpo esfacelado, despedaçado ou de corpos sem órgão. O que existe, é uma intensidade no interior de uma multiplicidade, num agenciamento de conexões que operam sobre o corpo. Dessa forma, é impossível criar para si um Corpo sem Órgãos, se não o vivendo. É ele mesmo uma zona de experimentação.

Logo, o corpo deixa de ser produto da ordem e torna-se intensivo de si mesmo, com aberturas que intensificam afetando não um órgão, mas um conjunto deles, criando suas zonas.

\section{Há um corpo que risca a docência...}

...borrando os papeis e manchando as paredes com sua imagem desviante. Os corpos são pontos moventes no mundo, uma manifestação, uma revolução, um lugar, uma ação, um campo de batalha (NEGRINI, 2017).

Ele é um entrelaçado de linhas intensas, que se lançam para inúmeras direções, alcançando outras linhas. Lugar das (re)criações, ligações de si. O corpo é uma colisão, lugar dos encontros, de força e mistérios. Ele é uma entrada e, simultaneamente uma saída, composto por seus desejos. Ele é um rabisco, um risco, um riso, uma mistura de cores e texturas. O corpo é essa potência, que vibra, que causa rachaduras. É habitado por linhas metamórficas, infiltração que molha, encharca, vaza. É um constante desvio, um fora do lugar, uma chegada. O corpo é um estranhamento, é essa marginalidade cambiante, que incomoda, embasa a visão. Ele é estilhaço, que se perde, se encontra, confunde a ordem das coisas.

Em Zaratustra, Nietzsche (2002, p. 47) evidencia "o corpo como uma razão em ponto grande, uma multiplicidade com um só sentido, uma guerra e uma paz, um rebanho e um Revista Interinstitucional Artes de Educar. Rio de Janeiro, V. 7, N. 1 - pág. 272-292 janeiroabril de 2021: "Pedagogias Vitais: Corpo, Desejo e Educação" DOI: 10.12957/ riae.2021.54627 
pastor". Composto por seus fluxos o corpo se desloca para além da sua materialidade, e assim como fez Nietzsche podemos nos perguntar se é possível saber “o que pode o corpo?”.

Como nos coloca (ROSE, 2001, p. 144), “nosso corpo não termina na pele, ele é um inacabável vir-a-ser". Um torna-se pelos intervalos do tempo, um entre e o meio, movido por suas forças, se referindo não à atividade do corpo, ao limite do mesmo, mas à sua potência, pelas ações as quais produzem efeitos e vibrações.

É possível ouvir os ecos indicando para outras indagações “o que pode o corpo?”, como: quais corpos estão sendo compostos na docência? Que conexões ligam o corpo ao lugar da existência? Quais contornos delineiam a masculinidade docente?

O corpo é lugar de acontecimentos de puro movimento com seu contorno e espessura, ele é o próprio espaço da existência no mundo. O corpo é muito mais do que supomos que ele seja.

Sua materialidade é marcada por divisores étnicos, simbólicos, sociais, de gênero e sexualidade. São processos indissociáveis e simultâneos que conferem ao corpo um caráter plástico, móvel e plural. São múltiplas suas formas de expressão e modos de organização e que sua materialidade está intimamente associada às suas maneiras de inserção no mundo. (ROSA; LIMA, 2013, p. 126)

O corpo é diluído por sua multiplicidade justamente por não estar fixo a uma estrutura normalizadora, e por isso ocupa o lugar da diferença, causando ecos, vibrações desejantes de uma docência sentida na hipoderme (sua camada mais profunda), mostrada na epiderme (sua camada superficial). Com seu corpo líquido encharca e rompe as densidades das paredes que comportam os lugares da educação, lugares esses que criam e acomodam corpos e traços, capturando os movimentos, as singularidades.

O recinto da educação é esse ao qual ocupamos e do qual não saímos feridos ou riscados por seus olhares, marcados por suas falas, escritos por suas páginas. Segundo (ROSA, 2009, p. 94).

Adentramos ao espaço da docência que parece configurar-se como um lugar anárquico onde se engendra uma política pedagógica capaz de abalar as estruturas políticas "generificantes" que estão a serviço de uma economia do corpo, do gênero e também da própria sexualidade.

Tomar as inscrições de uma "ciência verdade”, que os símbolos históricos e as páginas biológicas listaram e esquematizaram com suas cores, registrando suas leis, ajustando as tonalidades, reproduzidos ideias e armazenando seus princípios. As conexões: sexo - prazeres, 
sexualidade - fluxos, identidade - desejos são capturados no exercício das disciplinaridades, construindo formas especificas impressas na consumação reprodutiva das linearidades identitárias.

Foucault (1988) enfatiza que linearidades identitárias não se multiplicaram fora do poder ou contra ele, porém lá onde ele se exerce como meio para seu exercício, recriando em todo canto incitações a falar, dispositivos para ouvir e registrar, procedimentos para observar, interrogar e formular. Desenfurnam e obrigam a uma existência discursiva, imperativa, que impõe a cada um fazer de sua sexualidade um discurso permanente, aos múltiplos mecanismos que na ordem da economia, da pedagogia, da medicina e da justiça incitam, extraem, organizam e institucionalizam o discurso, prolixidade que nossa civilização organizou.

Para Louro (2000), é muitas vezes sutil, discreta, contínua, mas, quase sempre, eficiente e duradoura. Um processo de canalização que são ensinados, disciplinados, medidos, avaliados, examinados, aprovados (ou não), categorizados, coagidos e contidos. Em um mundo completamente mapeado e territorializado há espaço para fugir ao controle ou transgredir? Em se tratando das nossas práticas e saberes contemporâneos sobre o corpo, o que é transgressão? Ainda é possível transgredir? Há territórios corporais possíveis de produções transgressoras?

Na modernidade institucional, abordar a transgressão é também descrever formas de resistência ao poder, pois, para Foucault, o corpo capturado e produzido nas redes de poder da sociedade disciplinar e na biopolítica é também o corpo que resiste às manifestações do poder, já que "onde há poder há resistência". (CÉSAR, 2007, p. 03)

Isso nos possibilita pensar que os corpos e a masculidade na docência gestada na heterogeneidade do contexto pedagógico são fabricados em campos de guerrilha, minados no ajustamento dos modos de ser, paradoxalmente, lugar da (re)criação, da invenção; lugar movediço, da (r)existência. Por isso, são corpos que se forjam e fundem-se numa incorporação corpo-espaço, lugar onde docência acontece de múltiplos sentidos e vozes, berços onde são gestados e paridos corpos e masculinidades híbridos (ROSA, 2009).

Corpo e docência já tomam as linhas por seu processo de experimentação, sendo a si mesmo inscrição e impulso das forças afetivas e vibratória, pulsante pelo desejo. "Dilui-se a figura da masculidade, do qual sempre se tomou como ponto inicial para as afirmações instruídas para os homens, ferramentas subjetivas de identidade consumida" (DOEL, 2001, p.92). Pensamos esse processo como um agenciamento que está continuamente vazando em todas as direções. É o deslize do corpo, irregularidade das linhas, declives constantes, uma obra em andamento, incorporação singular, corrompida, híbrida, errante. 
O corpo-docente-viado vai delineando assim uma série de variações e perturbações pelas quais passa a (de)formar com sua imagem errante, sujando a educação com seu corpo desviante. Rompendo com o lugar habitável das densas corporificações sociais a bicha traça seu território existencial pelas linhas de fuga, porque essa existência tem chão, é situada, ainda que esse lugar não seja sedimento acumulado, propriedade demarcada, mas erosão, mutação contínua, atividade incessante de uma vida não-orgânica, não-organizada (ZAMBONI, 2013).

Desse modo, o corpo-bicha no transitar da docência é essa potência criadora, sempre a inventar-se, se (re)significando. Uma docência movediça que abre os buracos para fluir sua existência, criando córregos de si, preenchendo os espaços com seu corpo-líquido, escorrendo para novas direções. Por este pressuposto, Preciado (2011, p. 14)

O corpo já não é um dado passivo sobre o qual age o biopoder, antes uma potência que torna possível a incorporação prostética dos gêneros. A sexopolítica torna-se não somente um lugar de poder, mas, sobretudo, o espaço de uma criação na qual se sucedem e se justapõem os movimentos feministas, homossexuais, transexuais, intersexuais, transgêneros, chicanas, pós-coloniais. As minorias sexuais tornam-se multidões. O monstro sexual que tem por nome multidão torna-se queer, que não tem relação com um "terceiro sexo" ou um "além dos gêneros".

Ao colocar as coerências e estabilidades que no modelo construtivista fornecem um quadro compreensível e padronizado da sexualidade. "O queer revela um olhar mais afiado para os processos sociais normalizadores que criam classificações e por sua vez, geram a ilusão de sujeitos estáveis, identidades sociais e comportamentos coerentes e regulares" (MISKOLCI, 2009, p. 169).

Assim, desprender os fios, desatar o nó que amarram as sujeições de uma masculinidade unificada nas categorias identitárias. "A bicha deseja, e isso é insuportável, porque se ensina na masculinidade viril que o macho é o único capaz de desejar, de olhar com prazer, de medir e de avaliar. Mas a bicha também faz, rasga as noções naturalizadas de verdade, duvida, e tem prazer em desconcertar" (TAKARA, 2017, p. 161). Por isso, a bicha é potência, porque se desfaz dos jogos sociais, e assim ela ocupa o seu lugar dentro e fora da docência.

Como problematizador que se estabelece nas relações de poder, a bicha é esse impasse que quebra o lugar da normalidade, que se (re)veste de sua bichice. Corpo que trinca a educação com sua voz afeminada, dançante com seus passos deflorados. Ela está a borrar as salas com seus movimentos delicados. É ela quem escreve na lousa, mancha o quadro branco da 
civilização patriarcal. O corpo é seu lugar habitado por fluxos e linhas que cruzam outras linhas. São vibrações corporais que estilhaçam as estruturas.

O que temos na docência é esse corpo estilhaçado, quebrado, despedaçado que introduz a outros corpos, composto de linhas e fragmentos de si, de forças que intercruzam, chocam e escoam causando aberturas. Neles há linhas sempre em contínu(ação). Não há pontos específicos ao qual podemos determinar seu início ou seu fim, o que há são fluxos, atravessamentos e potências. Há um corpo fora das classificações, transgressivo, variante. Um corpo que borra os modos de ser/fazer docência.

No intervalo entre uma aula e outra a aluna observa: "Professor, você tem um jeito que eles não têm (...), mas isso não é algo ruim, é bom... tem sempre um sorriso no rosto, e também uma gargalhada mais solta, é mais livre...".

Há um corpo livre na sala de aula com suas linhas múltiplas. Um manifesto do corpo que se experimenta pelo riso, que expande, corrompe, ecoa, vibra e escapa por entre as fissuras causada no tremor de seu corpo errante, infiltrando-se numa educação olhada pelos cortes da diferença. Há no riso um vazamento da mecanização do corpo, como num disparo o riso rompe, ecoa para outros sentidos de si, trincam o lugar da educação retilínea, escoando por entre desejos sua sexualidade.

O riso aparece como uma aventura política (ROSA, 2009), visto que o corpo ao experimentar sua masculidade não deseja integrar-se aos ditames da normalidade e reivindicam irônica e alegremente outros modos de existência, ou seja, uma política que engendra outras formas de subjetivação, na amostra de sua sexualidade.

O silêncio do corpo é estilhaçado pelo riso, pelo excesso, no sentar, andar, falar, ensinar, escrever, sentir, ocupar, aparecer, gargalhar. Os ecos já tomaram para si o lugar arquitetado pela diferença, do estranho habitável, que se faz presente no alcance dos olhares, misturando sua imagem, oscilando entre tons e texturas, (re)criando suas faces, injetando outra postura, fazendo-se. “O riso se refere a um sentido de humor que questiona a seriedade e a normalidade da vida" (PEREIRA, 2008, p.508).

Corpo manifestado pelo riso, zumbido da normalidade estruturada. O riso é livre, o voo livre, borboletear é o voar das borboletas, leveza que desloca o corpo do chão estrutural das disciplinaridades. No chão da escola, o corpo faz sua viagem, seu voo, seu deslize, na mesma potência e delicadeza com o qual brincam as borboletas no ar, criando suas linhas, rasgando o vento com seu corpo delicado.

Dentro da sala de aula o aluno nota: "Professor você parece que não anda, voa... como uma borboleta, flutuando na sala!". 
São corpos em seu estado de experimentação, onde os olhares entre professor e alunos tomam os fluxos e as variações para compor novas vivências. O corpo flutua, se (de)forma nas passagens, nos deslizes dos contornos, gestando um outro corpo, descoberto no encontro dos olhares. O corpo é notado, contemplado por sua leveza, composto em sua delicadeza, solto. É o corpo que desafia a lógica linear, as simetrias. É o corpo impulso de suas próprias forças. É o corpo livre de si e das interpretações configuradas. É o corpo povoado de multiplicidades, que expulsou o organismo e sua organização, o que nos aproxima do "corpo sem órgão" de Deleuze e Guattari (1995), inspirados no dramaturgo e diretor de teatro Antonin Artaund.

A configuração da organização dos órgãos, alvo dos mitos, disciplinamentos e essencialização biológica. O organismo não é o corpo, o $\mathrm{CsO}$, mas um estrato sobre o $\mathrm{CsO}$, quer dizer um fenômeno de acumulação, de coagulação, de sedimentação que lhe impõe formas, funções, ligações, organizações dominantes e hierarquizadas, transcendências organizadas para extrair um trabalho útil (DELEUZE; GUATTARI, 1996).

O corpo é o relicário de um espaço infinito, de revelação e desvendamentos. O corpo é atravessado por pensamentos, impulsos, desejos, sensações, paisagens internas.

O corpo no estado sem órgãos permite uma reconstrução do exercício da vida, pois uma transformação interna ocorre, provoca novas formas de interação com o mundo e é um espaço infinito que se desdobra sobre si mesmo, está dentro e fora ao mesmo tempo. (SALLES, 2010, p. 07)

Trata-se da construção de um corpo mais pleno, vivo e intenso. Um corpo de resistência para o desejo e para a própria vida. Só que isso não é possível sem antes desconstruirmos o corpo que foi criado para servir docilmente aos poderes do campo social. Eis porque o CsO aparece em Artaud como uma declaração de guerra: guerra contra os órgãos, guerra contra o corpo ordenado, organizado, guerra, na verdade, contra o organismo em sua disposição e significância social. “Trata-se de um 'grito orgânico' do homem contra toda transcendência opressora. Trata-se de uma rebelião do próprio ser" (SCHÖPKE, 2017, p. 287).

No olhar da aluna, o corpo-docente se esvazia, distorce os vínculos da carne, como a metamorfose de Kafka (1997), ou mesmo o corpo elástico criado por Lewis Carroll (2002). É o corpo livre das costuras socioculturais, desconecto que transita no chão e no olhar do outro, traçando suas linhas, delineando uma nova imagem e composição de si, intenso e veloz em suas modulações. Ele ocupa todos os lugares, mas ele não cabe, nunca cabe, ele escoa num constante tornar-se, nunca é. Por isso está sempre se (de) compondo, reinventando-se a partir de quem o vê de quem o sente, metamorfoseando-se. 
Nessa circunstância, o corpo na docência experimenta as mudanças, mistura de cores, atravessamentos de olhares, variação de textura, rabisco das formas, esvaziados ou corrompidos pelos deslizamentos das linhas de vida. Nessas expressões encontramos as linhas de fuga ou a desterritorialização do corpo e seus devires, devir-animal, devir-inumano ao qual nos falou Deleuze e Guattari (1995), das intensidades desterritorializadas, da multiplicidade, devires infinitivos, intensidade que despersonaliza e multiplica.

Tem olhos na sala. Escancara uma voz densa, carregada de sacarmos, firme e certeiro no que pretende atingir: “Essas tuas aulas são cheias de viadagem!...”.

Meu corpo é incomodo. Minha voz arranha, meus passos machucam, meu cabelo assombra, meus movimentos ainda espantam, minha imagem confunde, meu lugar suja, minha aula perturba, minhas anotações borram, minhas avaliações reprovam, minha presença causa ânsia de vomito. Meu corpo você ler e tenta interpretar, interpelar. Nos teus olhos sou peça teatral, drama, romance, um assassinato. Na tua boca sente-me por meu sabor amargo, difícil de engolir, cospe-me. Meu riso é maior que o teu. Sou gargalhada, por isso te perfuro e te faço sangrar. Nas tuas veias, sou delírio, palpitações. Tenho um cheiro que te confunde, te causa certo enjoo. Doce ou amadeirado? Difícil decifrar. Na tua pele sou formigamento, queimação, inchaço, te causo alergia. Enquanto isso, nos teus olhos minhas cores se misturam, mudam de tonalidade, formam cores que te embriagam e te fazem tropeçar. Como água tu me bebes, estou nas tuas entranhas, rasgo tua pele e me libero, me liberto por tua camada mais fina e extensa assim, no teu corpo sou diluído, me deformo e escapo por entre teus poros. Minha sombra te assusta, meu corpo te ofende, minha voz te estremece. Meu corpo é lugar, existência, insistência, variação, por isso te fere.

Afinal que corpo é esse capaz de causar tanto incômodo, ânsia de vomito, palpitação? Esse é o corpo da bicha, que escapa, desliza, oscila entre outros corpos, solta o cabelo, libera os movimentos e voa incorpórea. Ela vive, existe e compõe o seu lugar de educador, lugar que a bicha quebra.

\footnotetext{
De outras ordens, a bicha é acusada, é chamada em público, ao andar na rua, ao entrar na escola, ao aparecer na mídia, a bicha é a outra: aquela que incita o machismo e a homofobia a constituírem-se e infringirem suas dinâmicas contra ela. (TAKARA, 2017, p. 154)
}

A bicha incomoda porque não está localizada em espaços físicos, todavia ocupa territórios de forma incômoda, causa náuseas e vertigens, é uma viagem para as alturas ou mesmo, uma invasão. 
Discorrer sobre as desconstruções desses espaços educacionais é refletir como esse movimento que remete ao estranho e ao excêntrico pode se articular com a educação, interrompendo a normalização e ajustamento de corpos e mentes. Como romper com binarismos e pensar a sexualidade, os gêneros e os corpos de uma forma plural, múltipla e cambiante? Como incorporar a teoria queer nas práticas pedagógicas?

Para ensaiar respostas a tais questões (LOURO, 2001, p. 550) diz que,

É preciso ter em mente não apenas o alvo mais imediato e direto da teoria queer - o regime de poder-saber que, assentado na oposição heterossexualidade/ homossexualidade, dá sentido às sociedades contemporâneas - mas também considerar as estratégias, os procedimentos e as atitudes nela implicados. A teoria queer permite pensar a ambiguidade, a multiplicidade e a fluidez das identidades sexuais e de gênero, mas, além disso, também sugere novas formas de pensar a cultura, o conhecimento, o poder e a educação.

A teoria queer representa claramente a diferença que não quer ser assimilada ou tolerada e, portanto, sua forma de ação é muito mais transgressiva e perturbadora. Por isso, " $a$ bicha em suas variações não assina sua localidade, pois ela é vertigem, cruzamento de territórios, estremecimento de fronteiras, linha transversal" (ZAMBONI, 2013, p.07).

Ao desestabilizar o olhar da diferença, o corpo da bicha altera os espaços por sua esquisitice, causando terremoto por seus movimentos fluídos, se revelando incomodo das figuras confortáveis aos olhos do mundo. Esse corpo-docente exposto com sua bichice, composto de aulas e viadagens, deslize e desejos, livros e rupturas, evidencia uma aula-ciências que escoa por outros córregos das marés educacionais.

O que a coordenação pedagógica pensa e age ao ver um professor-(des) viado entre os muros que cercam a educação? "Professor podes preparar seus alunos para uma apresentação artística para semana cultural da escola? É que o professor de matemática não tem muito jeito pra isso... não consigo nem imaginar ver ele dançando.”

O corpo-bicha na docência é apontado por sua masculidade cambiante, "que se espalha pelas denominações corporais ao qual a biologia, as relações, a mídia, a escola, a família e outros inúmeros lugares capturaram como produto de efeitos pronto e acabado em corpos subjetivados" (MISKOLCI, 2006, p. 682).

Nesse contexto, o corpo e sua bichice se desviam do corpo do outro, marcado no olhar que o afasta da imagem pronunciada na voz do coordenador pedagógico, que determina um lugar para corpo do professor de matemática composto de uma masculidade densa, acabada e fixa na imagem homem heterossexual reflexo das identidades rígidas. Seus movimentos são 


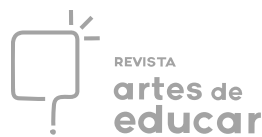

firmes e pontuados, sua virilidade marcada pelos movimentos dos braços, pelas passagens de pernas, pelas trocas de olhares, pelo riso livre, jogo de cintura. Movimentos permitidos ao seu corpo rígido de professor de matemática que aparece fixo nas estruturas e armadilhas sociais. Sendo nesse cenário do cotidiano escolar que o corpo por sua diferença é arrastado para dentro das categorias descritas para ser vista e compreendida. Para a bicha os movimentos do braço, o riso, o jogo de cintura são esquivados para não realizar tais movimentos, do contrário se denúncia. E quem disse que as bichas não querem denunciada, ser vista?

Esses corpos desestabilizam a heterossexualidade e a própria economia do poder, se rebelam contra a própria construção de corpos normais e anormais, subvertendo as normas de subjetivação da sexopolítica" O queer promove uma virada da força performativa dos discursos justamente na reapropriação das tecnologias de produção de corpos anormais, e entra no cenário atual como proposta de transformação na circulação dos discursos e na mutação dos corpos. (PEREIRA, 2008, p. 506)

Ao fazer essa excitação, "a bicha funde outros sentidos, oferece outras leituras $e$ coloca sua alegria como forma de disposição a intentar outros modos de educar e de informar, que convida outras formas de ser e, desse modo, não apenas uma, mas múltipla em sua potencialidade" (TAKARA, 2017, p. 155). A bicha bagunça a noção de naturalidade e normalidade, sua imagem contribui para pensar as práticas de pensar e ensinar sobre o que se tem como "verdade" que faz a masculinidade temer.

\section{As linhas deslizam}

... para compor outras linhas, sem pontuar uma conclusão. Não se finaliza um corpobicha-docente, compreendendo que se constitui de continuidades, vivências e experiências. Por esses deslizes temos um corpo-docente movente, que preenche o vazio das páginas na caderneta. É o corpo PRESENTE (grito). Corpo vibrante que treme as estruturas educacionais, acadêmicas e sociais. É o corpo dançante, movido pelos deslocamentos, de cores arco-íris, borboletas flutuantes (aquelas que a infância experimentou). Um corpo devir, que voa e ri, que sente, que está sempre a chegar, sem pressa, que deriva das passagens, que infiltra o lugar da docência ao transitar com sua viadagem. Esse corpo-bicha-professor é o que escapa, trinca, invade e causa as oscilações, variação das camadas epiteliais da existência, molhando o papel docente, bebendo da fonte de seus próprios rios para incorporar suas múltiplas faces existenciais.

Revista Interinstitucional Artes de Educar. Rio de Janeiro, V. 7, N. 1 - pág. 272-292 janeiroabril de 2021: "Pedagogias Vitais: Corpo, Desejo e Educação" DOI: 10.12957/riae.2021.54627 
Como bem nos disse Foucault (2006, p.88), "para conhecer-se a si mesmo é preciso dobrar-se sobre si (...)". Tomemos o exemplo do olho.

Sob que condições e como um olho pode se ver? Quando o olho de alguém se olha no olho de outro alguém, quando um olho se olha em um outro olho que lhe é inteiramente semelhante, o que vê ele no olho do outro? Vê-se a si mesmo. Portanto, uma identidade de natureza é a condição para que um indivíduo possa conhecer o que ele é. A identidade de natureza é, se quisermos, a superfície de reflexo onde o indivíduo pode reconhecer-se, conhecer o que ele é.

Podemos entrar na docência com esse reflexo do olhar, que cria suas feições e seus afetos no encontro do outro. Outro esse que é lugar do corpo, da sexualidade, das identidades flutuantes, lugar também da diferença, da essência, do estranhamento, da (re)significação, das invenções de si. Território dos atravessamentos, das vibrações. Lugar do professor, do aluno, das marés vazantes. Lugar do desvio, dos deslizamentos, das incorporações.

Esse corpo que se afirmar na bicha, corpo-professor, corpo-pesquisador, aparece como uma confissão que se deixa rasgar a mil pedaços, fazendo multiplicar o corpo por variação das formas existências, rompendo as estruturas, cavando os buracos, fazendo o corpo vazar como rio que escorre entre os galhos e folhagem, achando novas saídas.

\section{REFERÊNCIAS}

AURÉLIO, O minidicionário da língua Portuguesa. $4^{\circ}$ ed. Rev. Ampliada do minidicionário Aurélio, Rio de Janeiro, 2002.

AQUINO, J. G. A escrita como modo de vida: conexões e desdobramentos Educacionais. Educação e Pesquisa, São Paulo, v. 37, n. 3, 2011, p. 641- 656.

BUTLER, J. Problema de Gênero: feminismo e subversão da identidade. Tradução Renato Aguiar- Rio de Janeiro, Civilização Brasileira, 2003. 235 p.

BRITO, M. dos R. de. A escrita-devir como experimentação: para uma cartografia de si. Formação e docência: perspectiva da pesquisa narrativa e autobiográfica. (Orgs.) Silvia Nogueira Chaves; Maria dos Remédios de Brito, Ed: CEJUP, Belém, 2011. 255 p.

CALDA, R. B. C.; FERNANDES, J. G. dos S. As pedras do meu lugar: uma incursão nos nomes de lugares com itá na Amazônia oriental. Linguística, n. 1, 2015.

CÉSAR, M. R. de A. A (des)educação do corpo ou o pequeno desfile dos corpos contemporâneos e seus lugares da transgressão. Anais do XXIV Simpósio Nacional de História, São Paulo, 2007. 
DELEUZE, G.; PARNET, C. Diálogos. Tradução Eloisa Araújo Ribeiro, São Paulo: Escuta, 1998. $180 \mathrm{p}$.

DELEUZE, G.; GUATTARI, F. Mil platôs - capitalismo e esquizofrenia. Vol. 1. Tradução de Aurélio Guerra Neto e Célia Pinto Costa, Rio de janeiro, Ed. 34, 1995. 94 p.

DELEUZE, G.; GUATTARI, F. Mil platôs - capitalismo e esquizofrenia. Vol. 3. Tradução de Aurélio Guerra Neto et al, 34 ed. Rio de Janeiro, (Coleção TRANS), 1996.

DELEUZE, G.; GUATTARI, F. O Anti-Édipo: capitalismo e esquizofrenia 1. Tradução de Luiz B. L. Orlandi, São Paulo: Ed. 34, 2010. 560 p.

DELEUZE, G.; GUATTARI, F. Kafka: por uma literatura menor. Tradução Júlio Castañon Guimarães, Rio de Janeiro: Imago, 1977.

DELEUZE, G. A literatura e a vida. In: DELEUZE, G. Critica e Clínica. Tradução Peter Pál Pelbart, Coleção TRANS, 34 ed. São Paulo, 1971. 176 p.

DELEUZE, G. Foucault. Tradução Claudia Sant'Anna Martins, São Paulo, Editora Brasiliense, 2005. 142 p.

DELEUZE, G. A ilha deserta e outros textos. Editora Iluminuras, 2004.

DOEL, M. Corpos sem órgãos: esquizoanálise e desconstrução. In: SILVA, Tomaz Tadeu da. Nunca fomos humanos: nos rastros do sujeito. Belo Horizonte: Autêntica, 2001, p. 77- 110.

CARROLL, L. Alice no país das Maravilhas. Tradução Clélia Regina Ramos. São Paulo, 2002.

FOUCAULT, M. A hermenêutica do sujeito: Curso dado no College de France (1981-1982). Tradução Márcio Alves da Fonseca; Salma Tannus Muchail, ed. 2, São Paulo: Martins Fontes, 2006.

FOUCAULT, M. A escrita de si. In: FOUCAULT, M. Ética, sexualidade e política. Tradução: Elisa Monteiro Inês Autran Dourado Barbosa Rio de Janeiro: Forense Universitária, Ditos e Escritos V, 2004, p. 146-162.

FOUCAULT, M. O que é um autor. In: FOUCAULT, M. Ditos e Escritos: Estética, literatura e pintura, música e cinema. Rio de Janeiro, Forense Universitária, 2001. p. 264- 298.

FOUCAULT, M. História da sexualidade I: a vontade de saber. Tradução de Maria Thereza da Costa Albuquerque e J. A. Guilhon Albuquerque, 13 ed., Rio de Janeiro, Edições Graal, 1988. $125 \mathrm{p}$.

GREINER, C. Os novos estudos do corpo para repensar metodologias de pesquisa. Ciências e Artes, Caxias do Sul, v. 1, n. 1, 2011.

KAFKA, F. A metamorfose. Tradução: Modesto Carone, São Paulo: Companhia das letras, 1997.

LOURO, G. L. Corpo, escola e identidade. Educação \& Realidade, v. 25, n. 2, 2000. 75 p. 
LOURO, G. L. Teoria queer: uma política pós-identitária para a educação. Estudos feministas, n. 2, 2001, p. 541- 553.

MATOS, D. de O. Performe como texto, escrita como pele. Tese apresentada a banca examinadora da Pontifícia Universidade Católica, São Paulo, 2013. 196 p.

MISKOLCI, R. Corpos elétricos: do assujeitamento à estética da existência. Estudos Feministas. Florianópolis, 14(3): 272, 2006, p. 681- 693.

MISKOLCI, R. A teoria queer e a sociologia: o desafio de uma analítica da normalização Sociologias. Dossiê Sociologias, Porto Alegre, ano 11, n. 21, 2009, 150-182 p.

NIETZSCHE, F. Assim Falou Zaratustra. Tradução: José Mendes de Sousa. 2002.

NEGRINI, C. A. O corpo como campo de batalha: Resistências contemporâneas. Dissertação de Mestrado apresentado ao Programa de Pós-Graduação em Educação, Arte e História da Cultura da Universidade Presbiteriana Mackenzie, São Paulo, 2017, 83 p.

PEREIRA, P. P. G. Corpo, sexo e subversão: reflexões sobre duas teóricas queer. Dossiê Comunicação Saúde Educação, v. 12, n. 26, 2008, p. 499- 512.

PRECIADO, B. Manifesta contrassexual: Praticas subversivas de identidade sexual. Tradução de Maria Paula Gurgel Ribeiro, n 1, São Paulo, Edições, 2014. 223 p.

PRECIADO, B. Multidões queer: notas para uma Política dos "anormais". Tradução: Cleiton Zóia Münchow e Viviane Teixeira Silveira. Estudos Feministas, Florianópolis, 2011, p. 11-20.

PRIGOGINE, I. Ciência, Razão e Paixão. (Orgs) Edgard de Assis Carvalho; Maria da Conceição de Almeida, 2 ed., São Paulo, Editora Livraria da Física, 2009.

ROSA, R. M. da.; LIMA, P. de M. O corpo docente masculino: suas variações e (in)conformidades. Rev. Educação, Santa Maria, v. 38, n. 1, 2013, p. 123- 136.

ROSA, R. M. da. Corpos híbridos: experiencias, narrativas de si e (des)construção das masculinidades no magistério. Dissertação apresentada como requisito parcial a obtenção do grau de mestre em educação pela Universidade de Santa Catarina/ UDESC, Florianópolis, 2009, p. 11- 111.

ROSE, N. Inventando nossos eus. In: SILVA, Tomaz Tadeu da. Nunca fomos humanos: nos rastros do sujeito, Belo Horizonte: Autêntica, 2001, p. 137- 204.

SALLES, N. Antonin Artaud: o corpo sem órgãos. Periódico do Programa de Pós-Graduação em Artes Cênicas, O percevejo online, v. 02, n 01, 2010.

SILVA, R. G.; VALENÇA, K. M. Corpos efeminados na escola: a subalternidade em um espaço excludente. Revista Cadernos de Estudos e Pesquisa Básica, Recife, n. 1, 2016. p. $36-50$.

SCHERER, R. Deleuze e a questão homossexual: uma via não platônica da verdade. Tradução Eliana Aguiar, Lugar comum, n 7, 2016. p. 135-163. 
SCHÖPKE, R. Corpo sem órgãos e a produção da singularidade: A construção da máquina de guerra nômade. Rev. Filos., v. 29, n. 46, 2017. p. 285- 305.

TAKARA, S. Uma pedagogia bicha: homofobia, jornalismo e educação. Tese apresentada ao Programa de Pós-Graduação em Educação da Universidade Estadual de Maringá, como requisito para a obtenção do título de Doutor em Educação, Maringá, 2017, 177 p.

ZAMBONI, J. Cartografias Bicha. I Seminário Internacional Fazendo Gênero. (Anais Eletrônicos), n 10, Florianópolis, 2013.

ZAMBONI, J. Educação bicha: Uma anarqueologia da diversidade sexual. Tese (Doutorado em Educação) - Universidade Federal do Espírito Santo, Centro de Educação, 2016. 104 p.

\begin{abstract}
i Ao longo desse texto optamos em grafar o termo "viado" e não "veado", por ser assim ultizado pelas pessoas quando se referem, de forma pejorativa aos homossexuais, especialmente aos afeminados. Assim, o uso do termo localizado no seu lugar de resistência, faz com que o corpo tome força e movimento para romper e questionar os modos de estar professor, daquilo que o sistema educacional deixa evidente como um corpo-do(c)ente.
\end{abstract}

${ }^{i i}$ Licenciado em Ciências Naturais pela Universidade Federal do Pará (2013); Especializado em Educação Interculturalidade na Amazônia (2018); Mestrando em Educação em Ciências e Matemática (2019) no Instituto de Educação em Ciências e Matemática- IEMC. Faço pesquisa voltado para as discussões de gênero, corpo, sexualidade e Educação. Universidade Federal do Pará (UFPA). Pará - Brasil. ORCID iD https://orcid.org/00000002-0985-8631

iii Doutora em Filosofia da Educação pela Universidade Metodista de Piracicaba (UNIMEP). Pós-doutora em Filosofia da Educação pela Universidade Estadual de Campinas (UNICAMP). Professora adjunta IV da Universidade Federal do Pará (UFPA). Pará - Brasil. ORCID iD https://orcid.org/0000-0002-0478-5285

iv Comunidade tradicional amazônica, localizada a $12 \mathrm{~km}$ da sede do município de Bragança-PA, na Rodovia Bragança-Viseu, no km. 06, à margem direita do Rio Caeté. A peculiaridade do nome diz respeito à consistência das pedras, bem como à sua coloração. Devido à transformação fonética sofrida pela composição de itá + cuã + deua, na qual a supressão de $i$ - em posição pretônica, a forma ta conserva a constituição do nome "pedra" (CALDAS; FERNANDES, 2015).

v XY: geneticamente masculino. Segundo a medicina atual, um corpo é considerado geneticamente masculino se tem uma combinação cromossômica que possui pelo menos um cromossomo X e um cromossomo Y (PRECIADO, 2014, p.134).

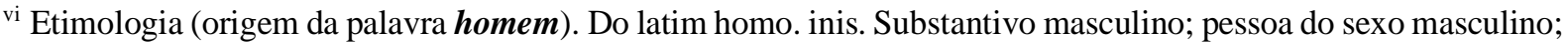
espécie humana; humanidade: a evolução social do homem; esposo, marido, companheiro. A criatura humana sob o ponto de vista moral: todo homem é passível de aperfeiçoamento. Ma. cho 1. Animal do sexo masculino. 2. Homem (física e sexualmente). 3. Valentão, fanfarão, 4. Dobras em duas dobras num pano, uma de cada lado. 5. Peça da dobradiça, do colchete, etc., que encaixa na outra, a fêmea. AURELIO, O minidicionário da língua Portuguesa. $4^{\circ}$ ed. Rev. Ampliada do minidicionário Aurélio, Rio de Janeiro, 2002. 